OPEN ACCESS

Edited by:

Zuoqiang Yuan,

Institute of Applied Ecology

(CAS), China

Reviewed by:

Andres Holz,

Portland State University,

United States

Guiomar Ruiz-Pérez,

Swedish University of Agricultural

Sciences, Sweden

Thomas A. Minckley,

University of Wyoming, United States

*Correspondence:

Peter Z. Fulé

pete.fule@nau.edu

Specialty section:

This article was submitted to Temperate and Boreal Forests,

a section of the journal

Frontiers in Forests and Global

Change

Received: 03 January 2020 Accepted: 23 April 2020

Published: 22 May 2020

Citation:

Hess VA and Fulé PZ (2020) Is a Mexican Pine Species Better Adapted

to the Warming Climate of the

Southwestern USA?

Front. For. Glob. Change 3:60.

doi: $10.3389 / f f g c .2020 .00060$

\section{Is a Mexican Pine Species Better Adapted to the Warming Climate of the Southwestern USA?}

\author{
Victoria A. Hess and Peter Z. Fulé* \\ School of Forestry, Northern Arizona University, Flagstaff, AZ, United States
}

Pinus leiophylla, or Chihuahua pine (PILE), and P. ponderosa, or ponderosa pine (PIPO), are two wide-ranging North American species with distributions that overlap in Arizona, USA. We compared the growth of 58 trees from three study sites over an elevation gradient at the northernmost point of PILE occurrence. Because the PILE trees were growing at the extreme edge of the species' range, we expected that PILE sensitivity to climate would be higher and growth performance would be reduced compared to PIPO. From 1918 to 2017, the study area became drier and warmer with precipitation declining by $\sim 9 \%$ while temperature rose by $\sim 5 \%$. We found that PILE tree-ring indices were more sensitive in terms of average year-to-year percent variation than those of PIPO and had higher variability in tree-ring variation in the 10 wettest vs. the 10 driest years. But PILE displayed higher absolute diameter growth rates as measured by basal area increment (BAl) and was less negatively correlated with warm monthly temperatures. Within species, low-elevation trees of both species tended to have greater sensitivity to climate over all variables assessed, but the differences were not statistically significant. The overall assessment of growth of paired trees of the two species showed the locally rare species PILE to perform approximately equally as well as the dominant species PIPO. Species migration is reshaping global forests but species found predominantly in Mexico with distributions coinciding closely with national boundaries have received insufficient research attention in the USA. We recommend cross-border, climate-focused, comprehensive studies on PILE and other species likely to migrate northward to provide critical information for conservation and management of forest resources.

Keywords: Pinus leiophylla, Pinus ponderosa, Arizona, tree-ring index, chronology, drought

\section{INTRODUCTION}

Interactions of anthropogenic climate change and disturbance have been shifting global vegetation patterns for decades with much greater changes expected in the near future. Examples of recent shifts include the upward movement of numerous species comprising plant communities on mountain ranges in desert (Brusca et al., 2013) and Mediterranean (Kelly and Goulden, 2008) ecosystems. Research interest has focused on differences in climate effects between leadingedge and trailing-edge populations. In dry forests of Pinus nigra in the Iberian Peninsula and north Africa, tree growth was most constrained by warm and dry conditions in the driest sites (Camarero et al., 2013). Latitudinal shifts are expected as well as elevational 
ones. Analysis of potential future climate conditions in British Columbia, for example, guided a common-garden experiment testing Pinus albicaulis planting up to $800 \mathrm{~km}$ NW of its current range (McLane and Aitken, 2012). Species' movements are likely to be more complex than simply uphill and poleward due to the numerous and complex physiological, demographic, and disturbance-related factors affecting species' distributions (Pecl et al., 2017). However, despite similar tendencies for movement among community members (Breshears et al., 2017), contemporary studies report individualistic species shifts (Brusca et al., 2013). Local conditions can outweigh broad geographical patterns, as in the Mediterranean where the southernmost $P$. nigra site in Morocco is more mesic than Spanish sites to the north (Camarero et al., 2013). Disturbance-mediated change associated with interactions between climate and wildfire or insect pathogens is also likely to affect shifting distributions in variable ways (Waring et al., 2009; Campbell and Shinneman, 2017; Parks et al., 2019).

Southwestern North America provides a useful context to investigate differential species characteristics that affect the likelihood of forest migration. Interesting features include the topographic complexity of the region with sky island forests on steep elevational gradients, separated by deserts. The forest taxa are complex resulting from northward migration of species from Mexican refugia during the Holocene, resulting in a relatively depauperate Petran (Rocky Mountain) flora meeting a much richer Madrean flora in the US states of Arizona and New Mexico (Brown, 1994). Tree-ring studies provide a temporally long context of climate-growth interactions at the scale of individual organisms (Truettner et al., 2018). Tree rings provided long, precisely dated information about growth and climatic sensitivity (Biondi, 1999). Comparisons among co-occurring southwestern North American species have provided insight about relative performance over elevational gradients (Adams and Kolb, 2005; Bickford et al., 2011) as well as drought-related mortality (Ogle et al., 2000).

Pinus ponderosa (Douglas ex Lawson, 1836), hereafter PIPO, and Pinus leiophylla (Schiede ex Schlechtendal et Chamisso, 1831), hereafter PILE, are two North American species that range over several thousand $\mathrm{km}$ from British Columbia to the USMexico border (PIPO) and from southern Mexico to Arizona and New Mexico, USA (PILE) (Figure 1). Substantial variability exists within both species, as might be expected given their vast ranges. Genetic study by Willyard et al. (2017) identified four distinct groups that they considered to reach the level of species within PIPO. In Mexico, Rodriguez-Banderas et al. (2009) separated PILE into $P$. leiophylla var. chihuahuana and three different groups within P. leiophylla var. leiophylla. Due to its economic and ecological importance, PIPO has been extensively studied in the forestry and ecology literature. The species comprises one of the principal sources of tree-ring data worldwide (International Tree-Ring Data Bank (ITRDB), 2019). PILE has been studied and some tree-ring chronologies have been developed, primarily in Mexico (Musálem and García, 2003), but the species has received limited attention in the USA given its rare and sparse distribution (Whittaker and Niering, 1975). Both species grow in pure and mixed montane stands, often with other conifers and Quercus species. There is extensive evidence of frequent fire disturbance in forests of both species, primarily through fire regimes of recurring low-severity fires (Swetnam and Baisan, 2003; Yocom Kent et al., 2017). Both species are characterized by relatively thick bark and self-pruning traits, which confer a degree of resistance to low-severity fire. PILE is also capable of resprouting following fire and a low degree of serotiny has been reported (Rodríguez-Trejo and Fulé, 2003; Baumgartner and Fulé, 2007).

The high rate of vegetation movement associated with global change (e.g., Brusca et al., 2013; Parks et al., 2019) makes it urgent to focus on likely "incoming" species, those expected to have a range advancement of a species along their leading edges as compared to historical elevational and latitudinal patterns, especially when their previously rare occurrence means that their attributes have not been compared to the currently dominant species. We selected the northernmost PILE populations in North America, which are interspersed with the dominant species PIPO (Figure 1), to study how both species were reacting to local climate in order to track trends and understand patterns for future climate predictions. Previous bioclimatic modeling studies gave contradictory predictions for PILE shifts; Rehfeldt et al. (2006) forecast that the species could move northward by $800 \mathrm{~km}$ and up in elevation by $600 \mathrm{~m}$ by 2090, while Sáenz-Romero et al. (2015) predicted diminishment or loss of USA habitat for PILE. Empirical growth data from the northern extreme of PILE's range would be useful to inform future forecasts.

Since we studied PILE at the extreme geographical limit of its range, we expected PIPO to have superior growth in relative and absolute terms. However, we recognize that the expected performance difference is a broad generalization due to the absence of regionally-specific data on PILE growth and physiology that would permit the formulation of more databased hypotheses. We expected to find differences in interannual climate sensitivity as well as intra-annual differences related to monthly climate factors. Arizona in general is substantially drier than the Mexican habitats of most of PILE's range (Figure 1). Specifically, we hypothesized that: $\mathrm{H}_{1}$, PILE tree-ring chronologies would have a higher sensitivity statistic (average interannual ring-width change) due to greater growth reductions in dry years. Because of expected severe growth reduction in the driest years, we hypothesized $\mathrm{H}_{2}$, Wet:Dry ratios calculated for ring-width indices (RWI) in the most wet and dry years would be higher for PILE than PIPO. Due to higher climatic sensitivity, $\mathrm{H}_{3}$, monthly precipitation values would be more positively correlated with RWI, and monthly temperature values would be more negatively correlated with RWI, for PILE than for PIPO trees. In terms of absolute growth as measured by basal area increment (BAI), we hypothesized that conditions at the range limit would result in: $\mathrm{H}_{4}$, PILE would have less growth; and $\mathrm{H}_{5}$, PILE would display greater BAI decline in drought years and reduced recovery from drought, as compared to PIPO. Finally, across the board, we expected that more xeric conditions at lower elevation meant that: $\mathrm{H}_{6}$, lower-elevation trees would perform less well than higher elevation trees. 


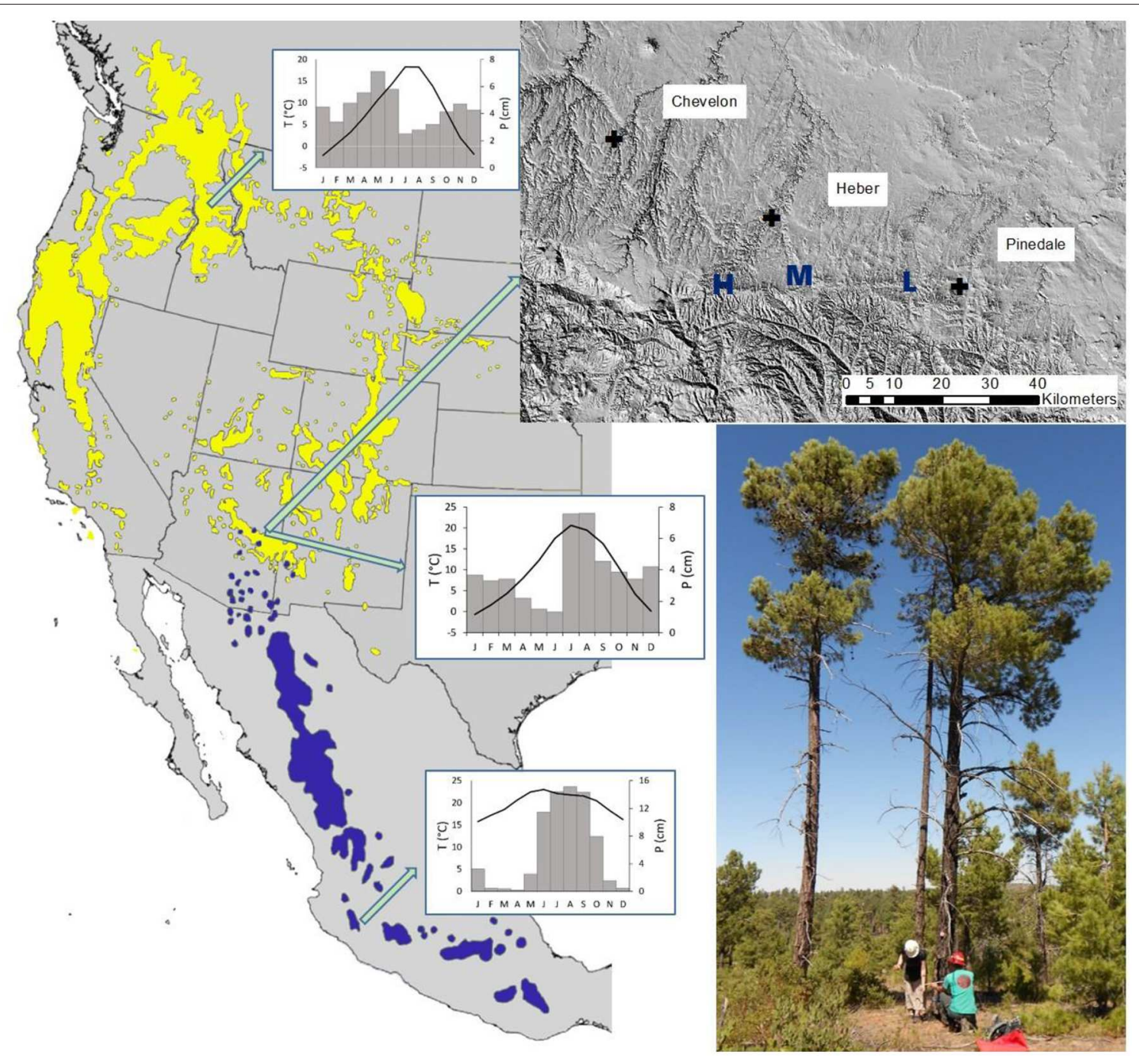

FIGURE 1 | Range of Pinus leiophylla, PILE (blue) and P. ponderosa, PIPO (yellow), maps from US Geological Survey. The study area is at the northernmost point of the PILE range. The inset map (upper right) shows the three study sites on the Mogollon Rim in Arizona, identified as High (H), Middle (M), and Low (L) elevation. The cross symbols mark the three weather stations. The inset photo (lower right) shows a pair of sampled trees with PILE on the left and PIPO on the right. Climate diagrams are from the study area (center), Nez Perce, Idaho, USA (Top), and Ciudad Guzmán, Jalisco, Mexico (Bottom).

\section{METHODS}

\section{Study Area}

Our study was conducted at the northernmost forest location of PILE in North America (Figure 1), on the Black Mesa Ranger District of the Apache-Sitgreaves National Forests near Heber, Arizona, USA. The elevation of the study area is between 2000 and $2,500 \mathrm{~m}$ with an average annual precipitation of around $46.5 \mathrm{~cm}$ (Western Regional Climate Center, 2017). Monthly temperatures average between -0.29 and $20.4^{\circ} \mathrm{C}$ with the lowest average temperatures in January and the highest in July. Climate data are discussed in more detail in the following section. We selected three study sites based on a fire ecology study by Baumgartner and Fulé (2007) which had 11 study plots. The three plots we chose represented the lower $(\mathrm{L}, 2,030 \mathrm{~m})$, middle
(M, 2,097), and high $(\mathrm{H}, 2,245)$ elevations of the Baumgartner and Fulé (2007) study. Soils are Typic Eutroboralfs and Udic Haplustalfs (for the middle elevation) which are slightly acidic soils or leached basic soils with a clay-enriched B horizon or subsoil. These soils are predominantly fine and mixed with gravelly sandy loams, rich in aluminum and iron. The high elevation soil is surrounded by Eutric Glossoboralfs which are characteristically influenced by volcanic ash. Soils data were taken from the Terrestrial Ecosystem Survey of the ApacheSitgreaves National Forests (USDA Forest Service, ApacheSitgreaves National Forests, 2019).

PILE is a rare and patchily distributed species in the forest, which is dominated by PIPO. Other species included white fir (Abies concolor Gord. \& Glen.), alligator juniper (Juniperus deppeana Steud.), Gambel oak (Quercus gambelii 
Nutt.), pointleaf manzanita (Arctostaphylos pungens Kunth), and Fendler ceanothus (Ceanothus fendleri Gray). Past management has included exclusion of the previously prevalent disturbance regime of frequent, low-severity fires (Huffman et al., 2015) and conversion of much of the forest structure to relatively homogeneous and young stands through even-aged harvesting systems. In 2002, the study area was burned by the 189,000 -ha Rodeo-Chediski fire, which was largely of high severity (Strom and Fulé, 2007; Shive et al., 2013). Baumgartner and Fulé (2007) found that about $37 \%$ of topkilled PILE trees resprouted after the fire.

\section{Climate Data}

We compiled climate data from three weather stations because no single station had a consistent or complete record of data. The three weather stations utilized are the Chevelon Ranger Station, the Heber Ranger Station, and the Pinedale Ranger Station (Western Regional Climate Center, 2017). We chose these stations because they were the closest to the study sites and had similar elevation. Numerous data values were missing from each of the three stations; in some cases, months or entire years were missing from one station or another. We compiled the data into a master data set for average monthly precipitation (1912-2017) and average monthly temperature (1917-2017). This ensured us a data set that had the least amount of missing data possible for a more accurate set of measurements. We converted the precipitation data set into water years (October 1 to September 30) because annual tree-ring growth is most closely related to the previous winter and the current-year growing season (Yang et al., 2014). We sorted water years to identify the top 10 wettest and top 10 driest water years. We also separately identified the top five wettest and top five driest water years for more thorough analyses. For consistency between precipitation and temperature data, we also converted the temperature data set into October 1 to September 30 periods.

\section{Tree-Ring Sampling}

At each of the three sites, we randomly sampled 10 mature Chihuahua pines, Pinus leiophylla or PILE. For each Chihuahua pine, we matched it with a comparable ponderosa pine (Pinus ponderosa) nearby with a similar diameter and height. By pairing similar trees, we were able to study differences in reactions from both species to the same climatic conditions. Chihuahua pines were chosen first as they are the less abundant of the two species in the area. For each tree, we measured the diameter at breast height $(\mathrm{DBH})$, the total height, and the height of the live crown base. For mapping, we also recorded the geographic position of each tree studied with a global positioning system (GPS) receiver. Every tree was cored at $\sim 40 \mathrm{~cm}$ above ground level, for a total of 60 cores.

\section{Lab and Analysis Procedures}

We glued cores to wooden core mounts and sanded them with progressively finer sandpaper until wood cells were clearly visible under magnification. We crossdated cores visually using narrow marker years (Stokes and Smiley, 1968) with the AZ527 Muletank ponderosa pine chronology (Graybill, 1986). Cores were measured with $0.001 \mathrm{~mm}$ accuracy on a sliding stage (Velmex Positioning System, 2017) with Measure J2X software. We checked crossdating through COFECHA software (Holmes, 1983). We successfully crossdated 58 of the 60 trees: all 30 PILE cores and 28 of the PIPO cores. We created separate data sets for each species (PILE and PIPO) and study site (L, M, H). Comparisons of relative and absolute growth between species was done at the level of the two species and three sites. The data were collected at the level of tree pairs in order to ensure that the study had equal representation between the two species of spatial distribution, including unmeasured attributes of microsites, as well as trees of approximately similar size. Tree attributes were compared with paired $t$-tests. All statistical analyses were done in $R$ version 3.5.2 (R Core Team, 2019) except where noted below. The alpha level was 0.05 for all tests.

We used the ARSTAN program (Cook and Krusic, 2014) to create tree-ring chronologies. Relative sensitivity of tree growth $\left(\mathrm{H}_{1}\right)$ was assessed as the mean "sensitivity" of the PILE and PIPO chronologies. This statistic is calculated as the mean proportional change from year to year in ring-width index (RWI) per tree (Speer, 2010), indicating the sensitivity or complacency of a treering series. The statistic called "sensitivity" in dendrochronology, the mean year-to-year ring-width variability, has been criticized as being ambiguous in describing tree-ring series, especially when comparing gymnosperm species that can have missing rings with angiosperm species that cannot because of the inherently different variances of such series (Bunn et al., 2013). We acknowledge the points made by Bunn et al. (2013). However, the literature on tree-ring growth comparisons similar to the present study reported the sensitivity statistic. We are interested in reporting similar statistics for comparison and we further note that all the comparisons in the cited literature and the present study involve conifer species of western North America, so the primary concern regarding comparisons across dissimilar taxa is moot. The expected relationship between the intercorrelation of the ring-width values among the trees comprising a chronology and sensitivity is that trees with stronger common signals are generally more sensitive. Sensitivity statistics were compared between species with paired $t$-tests for all trees together and by site. The expressed population signal (EPS) statistic, an estimate of the common variability in a chronology (Speer, 2010), was calculated for each chronology in ARSTAN.

We calculated a Wet:Dry $\left(\mathrm{H}_{2}\right)$ ratio by species and elevation to assess growth sensitivity to drought (Fekedulegn et al., 2003; Adams and Kolb, 2005). We summed monthly precipitation values from the climate dataset and selected the five and ten wettest and driest water years for analysis. We divided the average RWI in wet years by the average RWI in dry years to calculate the Wet-Dry ratio (W:D). Higher values of this ratio indicate higher differences in relative growth between exceptionally wet and dry years (Bickford et al., 2011). The W:D ratios for the top five and top ten wettest and driest years were compared with 2factor ANOVA, with the factors of species, elevation class (low, mid, high), and their interaction.

Monthly influence of precipitation and temperature on RWI values $\left(\mathrm{H}_{3}\right)$ was assessed with DendroClim 2002 software (Biondi and Waikul, 2004). Correlations were assessed over a 21-month 
period from January of the previous year through September of the current year. Statistical significance of correlation coefficients was assessed from bootstrapped estimates of 1,000 samples. Only statistically significant correlation coefficients, significantly different from 0 at the 0.05 probability level, are reported (Biondi and Waikul, 2004).

Absolute growth of PILE and PIPO $\left(\mathrm{H}_{4}\right)$ was assessed with basal area increment (BAI). We calculated the difference between the basal area $\left(\pi r^{2}\right)$ at year T and T-1 to calculate the annual incremental growth for year T (Johnson and Abrams, 2009). BAI measurements are expressed in $\mathrm{mm}^{2}$ year ${ }^{-1}$. We compared average BAI and 95\%-confidence intervals for PILE vs. PIPO trees and we calculated simple linear regressions through the data. In addition to comparing absolute growth in terms of BAI, we also considered comparing total aboveground biomass. There are regionally appropriate biomass equations for PIPO (Kaye et al., 2005). However, there are no biomass equations for PILE from the USA; the closest biomass equations for PILE were developed in northwestern Mexico over $500 \mathrm{~km}$ from the study area (Larreta et al., 2017). We chose to compare the 2dimensional BAI variable, measured here with high precision, rather than the 3-dimensional biomass variable which would be estimated with unknown precision as well as uncertain accuracy given that the PILE samples come from the extreme edge of the species' range. We compared growth responses with a repeated-measures ANOVA on BAI by species with year as the repeated variable. ANOVA assumptions of normality and homoscedasticity were met. Following an overall result of a statistically significant difference between species, BAI means in individual years were compared between species with Tukey's HSD test (JMP Pro 14.0.0, SAS Institute Inc., 2018).

We evaluated changes in tree growth associated with drought $\left(\mathrm{H}_{5}\right)$ for the five most severe drought years defined as the five lowest water years: 1928, 1955, 2000, 2002, and 2011. We calculated indices of Drought Sensitivity (DS) and Drought Recovery (DR) as defined by Sangüesa-Barreda et al. (2015). The DS statistic measures changes in the drought event compared to the average of the three previous years, while the DR statistic assesses the degree of return following the event:

$$
\begin{array}{r}
D S=\left[\left(B A I_{D}-B A I_{D-3}\right) / B A I_{D-3}\right] \times 100 \\
D R=\left[\left(B A I_{D+3}-B A I_{D-3}\right) / B A I_{D-3}\right] \times 100
\end{array}
$$

where $B A I_{D}$ is the BAI value for the drought year, $B A I_{D-3}$ is the mean BAI for the 3 years preceding the drought year, and $B A I_{D+3}$ is the mean BAI for the 3 years following the drought year. The mean BAI was calculated for 3-year intervals because it reflects the short-term BAI variation caused by drought (Sangüesa-Barreda et al., 2015). Index values were compared between species with $t$-tests (Sangüesa-Barreda et al., 2015).

\section{RESULTS}

From 1918 to 2017, the study area became drier and warmer. Precipitation in the study area declined by $\sim 4 \mathrm{~cm}$ ( $9 \%$ decrease) while temperature rose by $\sim 0.5^{\circ} \mathrm{C}$ ( $5 \%$ increase). These values are calculated as the difference between the start point and the end point of the central trendline for the corresponding graphs,

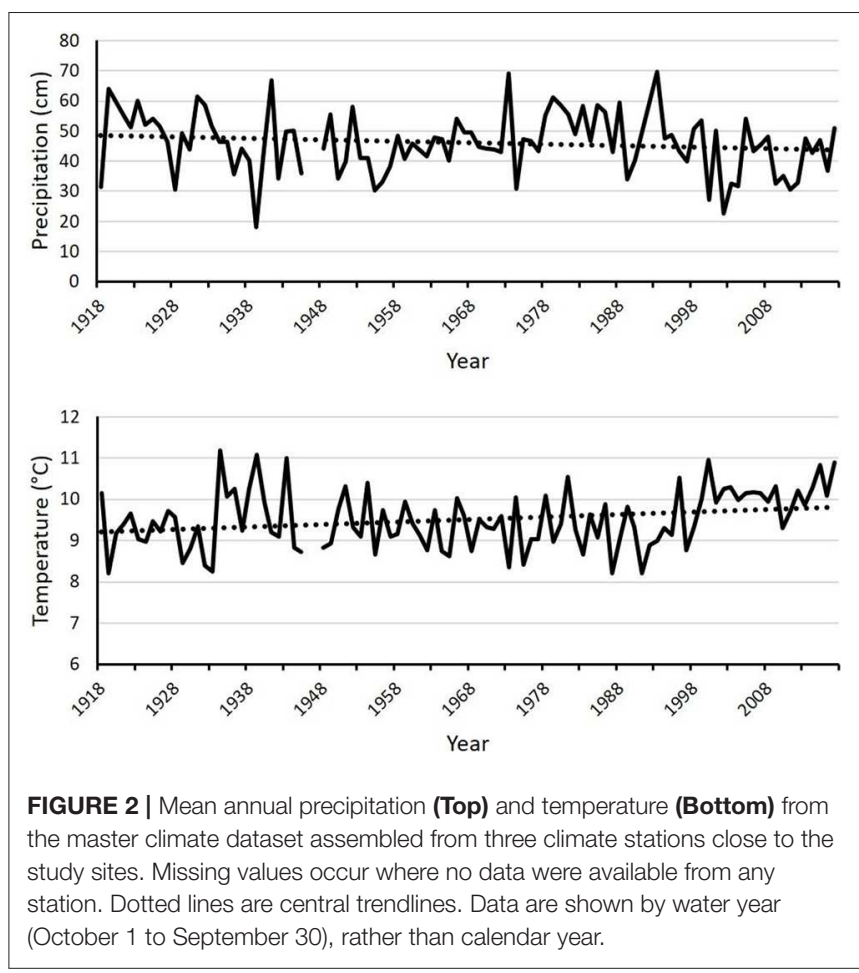

TABLE 1 | Individual tree summary statistics.

\begin{tabular}{lcccr}
\hline & DBH (cm) & Ht (m) & Crown Base Ht (m) & Age \\
\hline PILE & & & & \\
Mean & $38.2^{*}$ & $12.4^{\star}$ & $2.4^{\star}$ & 149.5 \\
S.E.M. & 1.4 & 0.4 & 0.3 & 6.6 \\
PIPO & & & & 168.8 \\
Mean & $34.8^{*}$ & $14.0^{\star}$ & $5.9^{*}$ & 7.4 \\
S.E.M. & 0.9 & 0.5 & 0.4 & \\
\hline
\end{tabular}

Means indicated with an asterisk were significantly different (paired t-test, $p=0.05$ ). S.E.M. = standard error of the mean. DBH is diameter at breast height $(1.37 \mathrm{~m})$. Ht is height $(m)$. Crown Base Ht is the height $(m)$ above ground of the lowest live branch.

illustrated by Figure 2. The master climate dataset was nearly complete except for 1946 and the first 6 months of 1947.

Although trees were selected in pairs to match as closely as possible (Table 1), there were statistically significant differences between several variables $(t$-test, $p<0.05)$. PILE trees had a significantly higher average $\mathrm{DBH}(3.4 \mathrm{~cm}$ higher, about $10 \%)$ but PIPO trees were significantly taller $(1.6 \mathrm{~m}$, about $11 \%)$ and had notably greater crown base heights $(3.5 \mathrm{~m}$ higher). PILE trees averaged 19.3 years younger than PIPO trees but the difference was not significant.

We developed standard and residual tree-ring chronologies for each species and elevation (Table 2). Intercorrelation statistics ranged from 0.49 to 0.72 . The three PILE chronologies averaged 0.65 vs. 0.57 for PIPO. PILE chronologies also had a higher average sensitivity, 0.34 vs. 0.31 for PIPO. Both intercorrelation and sensitivity statistics were highest at low elevation for both species and decreased with increasing elevation, except for the intercorrelation statistic for PILE. The expressed population 
TABLE 2 | Tree-ring chronology statistics for each species and elevation.

\begin{tabular}{lccc}
\hline & Sensitivity & $\boldsymbol{R}^{\mathbf{2}}$ & St. Dev. \\
\hline Low PILE & 0.369 & 0.716 & 0.036 \\
Low PIPO & 0.341 & 0.629 & 0.051 \\
Mid PILE & 0.337 & 0.595 & 0.075 \\
Mid PIPO & 0.313 & 0.550 & 0.038 \\
High PILE & $0.301^{*}$ & 0.624 & 0.029 \\
High PIPO & $0.272^{*}$ & 0.493 & 0.031 \\
All PILE & $0.336^{*}$ & 0.607 & 0.057 \\
All PIPO & $0.310^{*}$ & 0.540 & 0.049 \\
\hline
\end{tabular}

Means indicated with an asterisk were significantly different between species (paired $t$-test, $p=0.05$ ).

TABLE 3 | Wet:Dry ratios of ring-width index values by species and elevation for the top five and top 10 wettest and driest years.

\begin{tabular}{llllll}
\hline Low & Low & Mid & Mid & High & High \\
PILE & PIPO & PILE & PIPO & PILE & PIPO
\end{tabular}

Top $51.42(0.07) \quad 1.55(0.11) \quad 1.41(0.11) \quad 1.28(0.09) \quad 1.35(0.07) \quad 1.27(0.06)$

Top $101.36(0.05) \quad 1.31(0.05) \quad 1.36(0.06) \quad 1.30(0.04) \quad 1.37(0.05) \quad 1.20(0.04)$

Values are mean and (standard error). The only statistically significant difference was between species for the W:D Top 10 category (2-factor ANOVA).

signal (EPS) statistics exceeded 0.85 in PILE and PIPO chronologies from 1875 to present. Traditionally this value has been used to suggest that the chronologies represented a coherent, stand-level signal (Speer, 2010), although the reliability of this interpretation has been questioned (Buras, 2017).

Growth in the wettest years ranged from 20 to $40 \%$ higher than in the driest years, indicated by the Wet:Dry growth ratios in the most extreme 5 and 10 years in the precipitation record (Table 3). None of the factors (species, elevation, and interaction) was statistically significant in the W:D Top 5, but PILE was significantly higher than PIPO in Wet:Dry ratio in the Top 10 comparison ( $p=0.026)$. The wet:dry ratios varied with elevation but it was not a statistically significant factor. PIPO displayed the greatest variability in ratios with elevation, 1.55 at low elevation, as compared to 1.27 at high elevation.

Seasonal influences of precipitation and temperature were similar between the two species but PIPO was more consistently significantly negatively influenced by warm temperatures (Figure 3). Precipitation in the previous winter, especially December, and current-year May to July was positively correlated with ring-width index for both species. The highest correlations for PILE were in June while the highest for PIPO were in the previous December, especially at the low elevation site. Temperatures were negatively correlated with ring-width index for both species, but PIPO was negatively affected in more months and years. Only 4 out of 63 possible months (21 months of analysis $\times 3$ elevation zones) had significant negative correlations lower than -0.20 (orange color in Figure 3 ) for all three PILE chronologies. The high-elevation PILE chronology had no month with a notable negative effect of temperature. In contrast, 13 months had significant negative correlations lower than -0.20 for all the PIPO chronologies. Negative relationships were notable in the late winter of the previous year (Feb-Mar) and current-year spring (March-June).

Absolute growth of PILE trees as measured by basal area increment (BAI) was significantly higher than PIPO trees during the century from 1918 to 2017 (Figure 4). The post-hoc comparison of individual years showed statistically significant higher growth of PILE in 41 out of the 100 years (Figure 4). The consistently faster basal area growth of PILE trees explains the fact that PILE had higher average DBH but lower age than PIPO (Table 1).

Drought sensitivity (DS) varied from $+18 \%$ to $-80 \%$ for PILE and $+11 \%$ to $-78 \%$ for PIPO (Figure 5). The most pronounced declines were in the 2000 and 2002 drought years, and these two drought years were close enough together to enter reciprocally into the DS and DR formulas. Drought recovery (DR) statistics ranged from $+9 \%$ to $-33 \%$ for PILE and $+25 \%$ to $-45 \%$ for PIPO. The 2000 drought had the most negative DR value for both species. Both species had negative DR values for all three drought years in the twenty-first century. The two species had statistically significant differences in only one of the five drought years, 1928 (Figure 5).

\section{DISCUSSION}

Despite endeavoring to closely match PILE and PIPO trees in the field, we found that the PILE trees averaged 10\% larger in diameter but PIPO trees averaged about $11 \%$ taller. These differences may affect the comparisons made in this study. However, our careful search in the fieldwork makes us confident that the data set represents the best possible matches available at the isolated northernmost patches of PILE. The fact that the differences in diameter vs. height were split between the species, rather than one species having overall bigger trees, suggests that there is not a systematic size bias affecting the results.

Growth of PILE and PIPO at the northernmost location of PILE in North America was relatively similar, with the study hypotheses of reduced PILE performance being supported in some aspects and rejected in others. We found greater tree-ring sensitivity in PILE than PIPO, as expected in $\mathrm{H}_{1}$, and significantly higher variability in $\mathrm{W}: \mathrm{D}$ ratio of PILE in one of two comparisons $\left(\mathrm{H}_{2}\right)$, with no difference in the other. Other hypotheses of reduced PILE performance relative to PIPO were rejected. PILE was less negatively correlated with warm monthly temperatures $\left(\mathrm{H}_{3}\right)$ and had greater sustained absolute growth as measured by BAI $\left(\mathrm{H}_{4}\right)$. The species were nearly indistinguishable in drought sensitivity and recovery in terms of BAI $\left(\mathrm{H}_{5}\right)$; the only statistically significant result was in one drought year (1928) out of the five studied, in which PIPO performed better than PILE. The final hypothesis $\mathrm{H}_{6}$, that low-elevation trees of both species would have greater sensitivity to climate over all variables assessed, was not supported, although non-significant trends were consistent with better growth at higher elevation. In sum, assessment of growth of paired trees of the two species showed PILE to perform approximately equally to the dominant species PIPO. Each of the different comparisons offers specific insights into the two species, suggesting potential mechanisms and hypotheses for future research. 


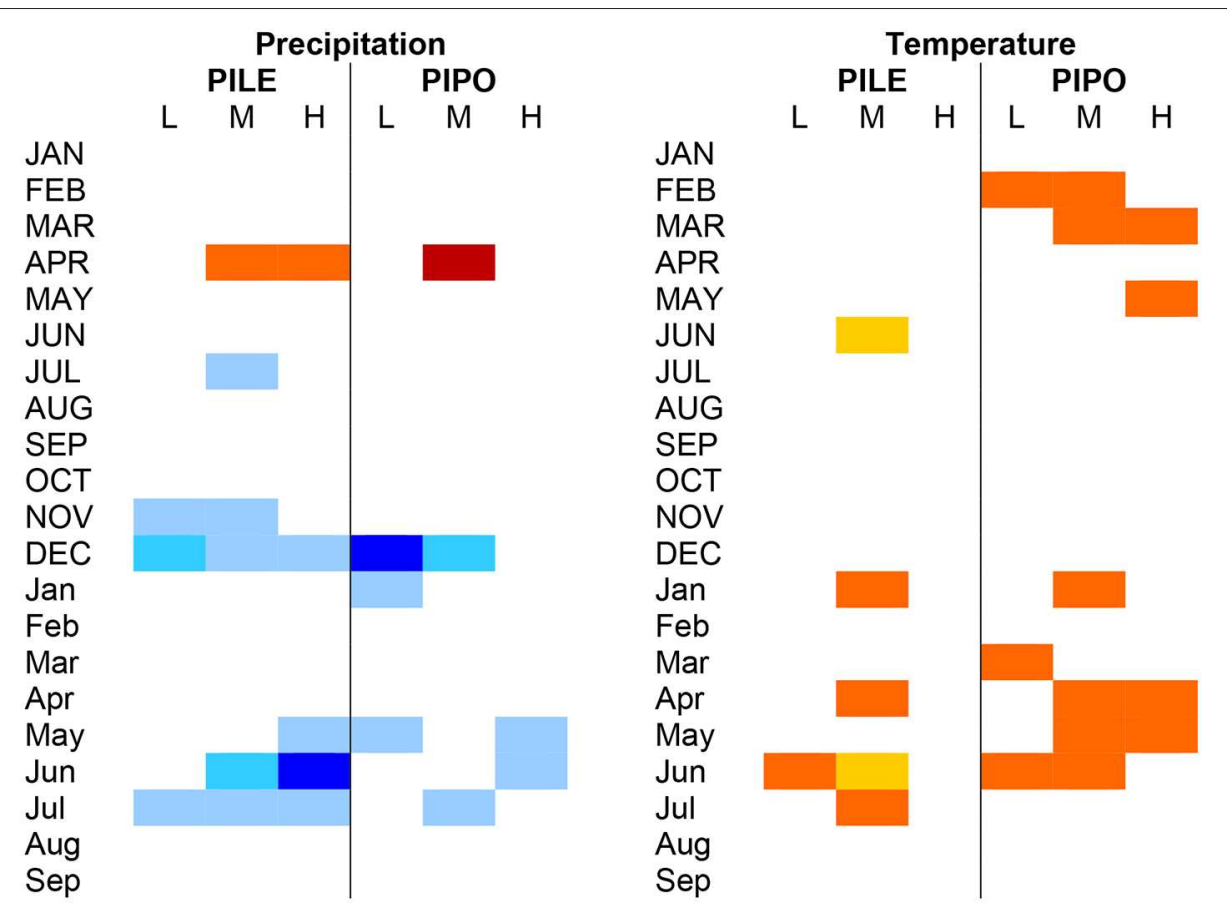

FIGURE 3 | Statistically significant correlations between ring width index values and monthly precipitation (Left) and temperature (Right). Correlations were calculated for the previous year (JAN, FEB, etc.) and current year (Jan, Feb, etc.). Months with a correlation coefficient $>|0.20|$ are shown in color. Darker shades of blue indicate increasingly positive correlations (max. value 0.42) and darker shades of red indicate increasingly negative correlations (min. value -0.33 ).

In contrast to our initial expectation that PILE trees at the extreme northern limit of the species' range would be more sensitive to climate and grow less than PIPO, many measures of sensitivity and growth actually showed superior PILE performance. One logical explanation for the reduced temperature sensitivity of PILE as compared to PIPO is the generally higher temperature over the Mexican range of the southern species. As indicated by the representative climate diagrams in Figure 1, the peak in average annual temperatures was only slightly higher in Ciudad Guzmán, Jalisco, than our study area, but the cooler months had much higher temperatures than the Arizona site. The climate of Nez Perce, Idaho, where only PIPO is found, had much cooler winter, spring, and fall temperatures and a lower summer peak than Arizona or Jalisco. Given the likely adaptation of PILE to warmth across its range, this may explain its reduced temperature sensitivity in Arizona and may indicate superior resilience to warming temperatures forecast for the southwestern US (Seager et al., 2007). The genetic basis for differential temperature responses within species has not been studied for PILE but Shinneman et al. (2016) reported that different evolutionary lineages of PIPO had distinct climate niches. Seasonal differences in water availability may also play a greater role in the future. PIPO in Arizona is known to rely heavily on winter precipitation for annual wood increment (Kerhoulas et al., 2017), while PILE occupies variable climates but with a tendency toward domination by summer precipitation (Musálem and García, 2003). Southwestern USA climates are predicted to have much drier winters as climate shifts over

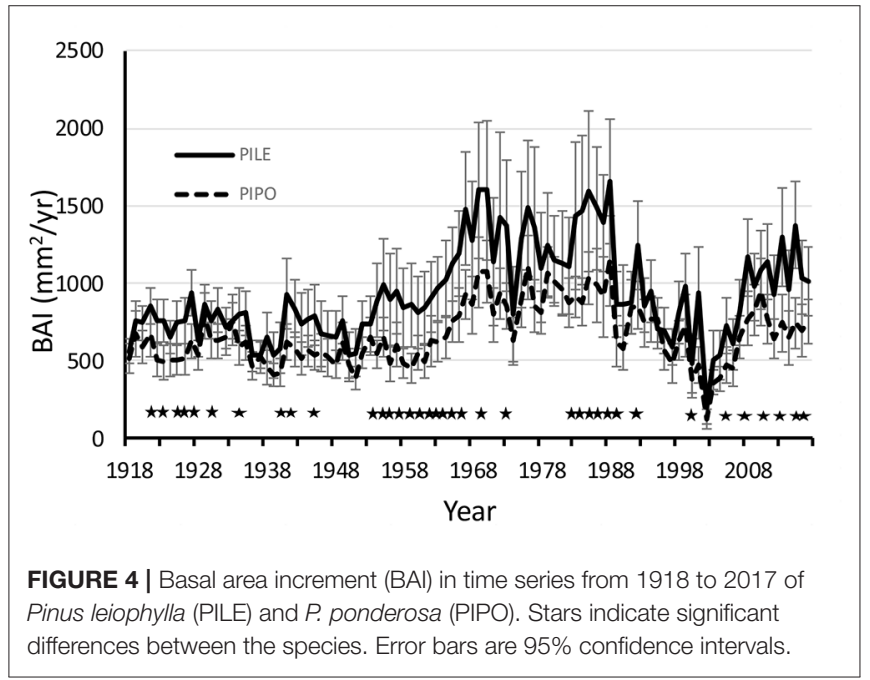

the twenty-first century (Seager et al., 2007; Klos et al., 2014). Summer rainfall in the Southwest is less well-understood and the interaction of the monsoon with climate change is an area of active research. While uncertainty about future seasonal water availability remains high, these factors suggest that PILE may have an advantage relative to PIPO.

Another possible factor influencing PILE performance is the observation that the scattered PILE stands on the ApacheSitgreaves National Forests tend to occur on light-colored, rocky soils with little organic matter or herbaceous growth, referred to 

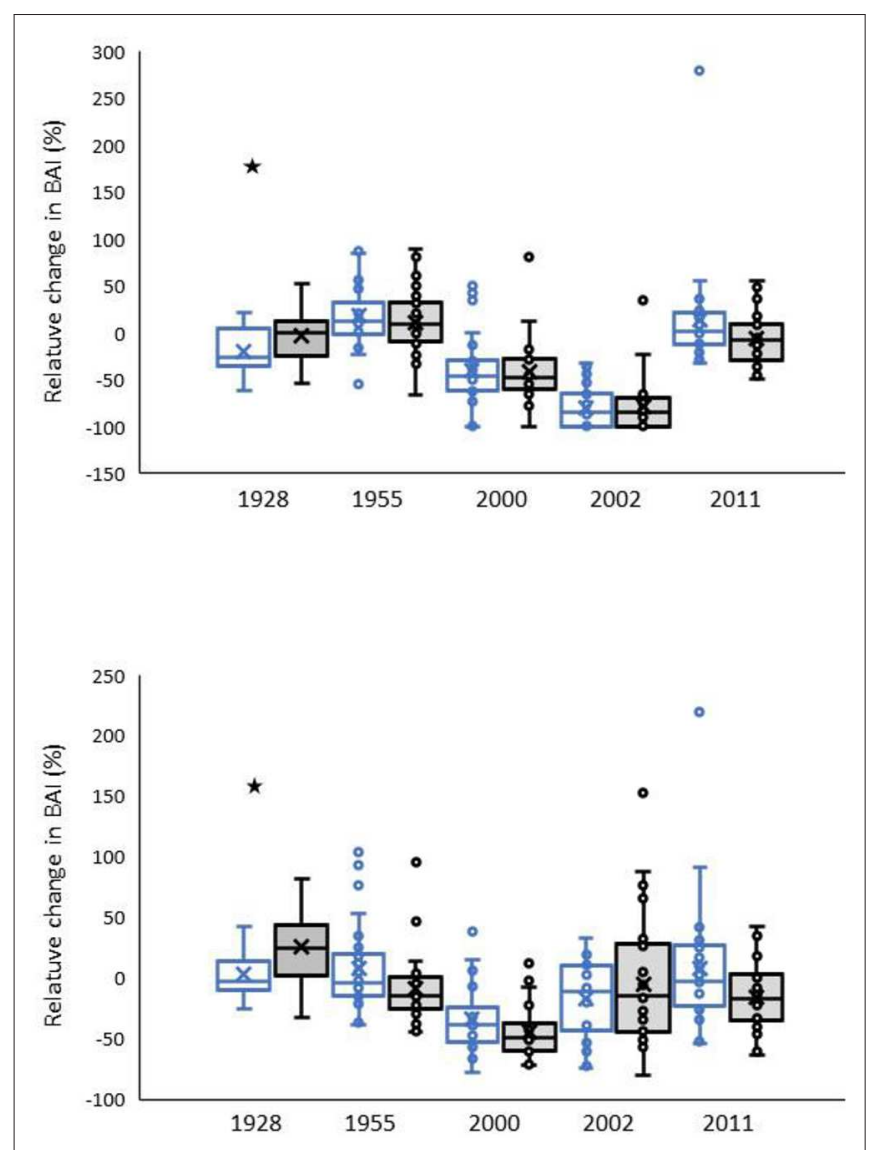

FIGURE 5 | Indices of drought sensitivity, DS (Top), and drought recovery, DR (Bottom). Indices reflect the proportional anomaly in BAl calculated in 3-year windows before drought (DS) or 3 years pre- and 3 years post-drought (DR). Pinus leiophylla open symbols, P. ponderosa shaded symbols. Stars indicate significant differences between the species.

by local foresters as the "Gobi Desert" (G. Richardson, personal communication, A-S National Forests). These patches of lightcolored soil occur at scales of $10^{0}-10^{1}$ hectares, smaller than the minimum map units, around $10^{2}$ ha, of the Terrestrial Ecosystem Survey (TES). Therefore, we could not characterize the unique soils associated with PILE stands. However, if the soils are in fact less productive than those of the surrounding PIPO-dominated forest, we speculate that the poor soils may be related to the superior performance of PILE trees by reducing the competitive capability of PIPO. This would be a useful question for future research comparing the physiological performance of both species. Furthermore, as climate conditions warm in future decades, more of the soils in this elevational band are likely to decline in productivity due to reduced growth, declining litter inputs, and fire and erosional processes. Climate-induced soil degradation could contribute to PIPO decline and PILE advance during the twenty-first century.

Southwestern USA wildfires have been increasing in size (Yocom et al., 2019) and severity (Singleton et al., 2019), and severe burning is linked to climate warming (Mueller, 2019). As is the case with many other dry forest types worldwide, these trends are expected to continue (Parks et al., 2019). Studies suggest that the "trailing edge" of dry coniferous forest distributions, such as PIPO close to its southern limit in this case, may be at risk of deforestation (Parks et al., 2019). After severe wildfires, PILE has a distinct advantage over PIPO due to its resprouting habit (Baumgartner and Fulé, 2007). However, PILE is a relatively weak resprouter as compared to another sprouting pine, Pinus canariensis (Molina-Terrén et al., 2016). Less than half of the PILE trees measured by Baumgartner and Fulé (2007) resprouted after being top-killed by fire and those that were successful tended to be smaller in size-implying reduced belowground reserves to support growth-and less severely burned. Increasing recurrence of severe fires can degrade the capability of trees to resprout, challenging the concept of resprouters as "resilient" to fire (Fairman et al., 2019). In addition, although PIPO regeneration is notoriously variable following wildfire in the Southwest (Ouzts et al., 2015), PIPO has been shown to regenerate vigorously in the study region following the 2002 Rodeo-Chediski fire (Owen et al., 2017). Therefore, it would be premature to assume that severe wildfires will necessarily favor PILE at the expense of PIPO on the Mogollon Rim of Arizona in the near future.

The broader question that merits further investigation, however, is the potential role of PILE as a dominant coniferous forest species in the southwestern USA at a time when climate trends appear unfavorable to PIPO (Azpeleta Tarancón et al., 2014). We found that PILE trees at the northern limit of its range grew faster in diameter and were less sensitive to warm temperatures than co-occurring PIPO trees. Coupled with their resprouting habit, these attributes suggest that PILE could be relatively well-adapted to future conditions of warmer temperatures, reduced soil productivity, and more frequent and severe wildfires. We suggest that greater attention should be paid to this species and other species that reach their northern limits at or near the USA-Mexico border, such as P. lumholtzii, $P$. durangensis, $P$. strobiformis, and $P$. engelmannii. Some of these species have been well-studied in Mexico. For example, $P$. durangensis is a widespread species which forms a substantial timber stock in northern Mexico (Návar et al., 2013). However, PILE, P. lumholtzii, and P. engelmannii are of limited commercial importance and thus their silvics and ecology have received little study. Even in the situation where PILE has been evaluated at a national Mexican scale in terms of genetics (RodriguezBanderas et al., 2009) or silvics (Musálem and García, 2003), the research stopped at the border. We recommend crossborder, climate-focused, comprehensive studies such as recent work by Shirk et al. (2018) on P. strobiformis. Our present interest is focused on pines but Madrean oaks and other wideranging tree species such as Juniperus deppeana also merit attention as species likely to expand in the USA. Research should include within-species genetic variation that may be related to climate sensitivity.

Species migration, both unassisted and assisted, is reshaping global forests. Research on natural experiments, such as the observational tree-ring study described here, and controlled experiments such as common-garden plantings (Patterson et al., 2018) provide critical information for conservation and management of forest resources. The ecosystem services provided by forests are especially critical and most at risk in semi-arid settings (Yazzie et al., 2019); it may be in these regions 
where knowledge about the performance of incoming migratory species will prove the most useful.

\section{DATA AVAILABILITY STATEMENT}

The datasets generated for this study can be found in the International Tree-Ring Data Bank (https://www.ncdc.noaa.gov/ data-access/paleoclimatology-data/datasets/tree-ring).

\section{AUTHOR CONTRIBUTIONS}

$\mathrm{PF}$ and $\mathrm{VH}$ designed the study. $\mathrm{VH}$ led the tree-ring dating. PF led the analysis. All authors wrote the manuscript, and contributed to manuscript revision, read, and approved the submitted version.

\section{REFERENCES}

Adams, H. D., and Kolb, T. E. (2005). Tree growth response to drought and temperature in a mountain landscape in Northern Arizona, USA. J. Biogeogr. 32, 1629-1640. doi: 10.1111/j.1365-2699.2005.01292.x

Azpeleta Tarancón, A., Fulé, P. Z., Shive, K. L., Sieg, C. H., Meador, A. S., and Strom, B. (2014). Simulating post-wildfire forest trajectories under alternative climate and management scenarios. Ecol. Appl. 24, 1626-1637. doi: 10.1890/13-1787.1

Baumgartner, K. H., and Fulé, P. Z. (2007). Survival and sprouting responses of chihuahua pine after the rodeo-chediski fire on the Mogollon Rim, Arizona. West. North Am. Nat. 67, 51-56. doi: 10.3398/15270904(2007)67[51:SASROC]2.0.CO;2

Bickford, I. N., Fulé, P. Z., and Kolb, T. E. (2011). Growth sensitivity to drought of co-occurring Pinus spp. along an elevation gradient in Northern Mexico. West. North Am. Nat. 71, 338-348. doi: 10.3398/064.071.0302

Biondi, F. (1999). Comparing tree-ring chronologies and repeated timber inventories as forest monitoring tools. Ecol. Appl. 9, 216-227. doi: 10.1890/ 1051-0761(1999)009[0216:CTRCAR]2.0.CO;2

Biondi, F., and Waikul, K. (2004). DENDROCLIM2002: a C++ program for statistical calibration of climate signals in tree-ring chronologies. Comput. Geosci. 30, 303-311. doi: 10.1016/j.cageo.2003.11.004

Breshears, D. D., Huxman, T. E., Adams, H. D., Zou, C. B. and Davison, J. E. (2017). Vegetation synchronously leans upslope as climate warms. PNAS 105, 11591-11592. doi: 10.1073/pnas.0806579105

Brown, D. E. (1994). Biotic Communities: Southwestern United States and Northwestern Mexico, 2nd edn. Salt Lake City, UT: University of Utah Press.

Brusca, R. C., Wiens, J. F., Meyer, W. M., Eble, J., Franklin, K., Overpeck, J. T., et al. (2013). Dramatic response to climate change in the Southwest: Robert Whittaker's 1963 Arizona Mountain plant transect revisited. Ecol. Evol. 3, 3307-3319. doi: 10.1002/ece3.720

Bunn, A. G., Jansma, E., Korpela, M., Westfall, R. D., and Baldwin, J. (2013). Using simulations and data to evaluate mean sensitivity $(\zeta)$ as a useful statistic in dendrochronology. Dendrochronologia 31, 250-254. doi: 10.1016/j.dendro.2013.01.004

Buras, A. (2017). A comment on the expressed population signal. Dendrochronologia 44, 130-132. doi: 10.1016/j.dendro.2017.03.005

Camarero, J. J., Manzanedo, R. D., Sanchez-Salguero, R., and Navarro-Cerrillo, R. M. (2013). Growth response to climate and drought change along an aridity gradient in the Southernmost Pinus nigra relict forests. Ann. Forest Sci. 70, 769-780. doi: 10.1007/s13595-013-0321-9

Campbell, J. L., and Shinneman, D. J. (2017). Potential influence of wildfire in modulating climate-induced forest redistribution in a central Rocky Mountain landscape. Ecol. Process. 6:7. doi: 10.1186/s13717-01 7-0073-9

Cook, E. R., and Krusic, P. J. (2014). Program ARSTAN Users Manual. Tucson, AZ: Laboratory of Tree-Ring Research, University of Arizona.

\section{FUNDING}

This work was provided by the Interns 2 Scholars program and the Forest Ecology Lab at the School of Forestry, Northern Arizona University.

\section{ACKNOWLEDGMENTS}

Thanks to Molly Peige Barrett and Don Normandin for field assistance. Gayle Richardson and Eric Robertson of the Apache-Sitgreaves National Forest provided helpful comments. Taylor Joyal and the Interns2Scholars program at Northern Arizona University supported $\mathrm{VH}$. Angie Moline and Joe Crouse provided graphical and technical support.

Douglas ex Lawson (1836). "Pinus ponderosa," in The Gymnosperm Database. Available online at: https://www.conifers.org/pi/Pinus_ponderosa.php (accessed March 5, 2019).

Fairman, T. A., Bennett, L. T., and Nitschke, C. R. (2019). Short-interval wildfires increase likelihood of resprouting failure in fire-tolerant trees. J. Environ. Manage. 231, 59-65. doi: 10.1016/j.jenvman.2018.10.021

Fekedulegn, D., Hicks, R. R., and Colbert, J. J. (2003). Influence of topographic aspect, precipitation and drought on radial growth of four major tree species in an Appalachian watershed. Forest Ecol. Manage. 177, 409-425. doi: 10.1016/S0378-1127(02)00446-2

Graybill, D. A. (1986). Ponderosa Pine Tree-Ring Chronology: Muletank - PIPO ITRDB AZ527. International Tree-Ring Data Bank. Available online at: https:// www.ncdc.noaa.gov/paleo-search/study/3385 (accessed February 4, 2019).

Holmes, R. L. (1983). Computer-assisted quality control in tree-ring dating and measurement. Tree-Ring Bull. 43, 69-78.

Huffman, D., Zegler, T., and Fulé, P. Z. (2015). Fire history of a mixed conifer forest on the Mogollon Rim, northern Arizona, USA. Int. J. Wildland Fire 24, 680-689. doi: 10.1071/WF14005

International Tree-Ring Data Bank (ITRDB) (2019). Available online at: https:// www.ncdc.noaa.gov/data-access/paleoclimatology-data/datasets/tree-ring (accessed February 4, 2019).

Johnson, S. E., Abrams, M. D. (2009). "Basal area increment trends across age classes for two long-lived tree species in the eastern US," in TRACE - Tree Rings in Archaeology, Climatology, and Ecology, Vol. 7, eds R. Kaczka, I. Malik, P. Owczarek, H. Gärtnet, G. Helle, and I. Heinrich (Potsdam: GFZ Potsdam, Scientific Technical Report 09/03), 127-134.

Kaye, J. P., Hart, S. C., Fulé, P. Z., Covington, W. W., Moore, M. M and Kaye, M.W. (2005). Initial carbon, nitrogen, and phosphorus fluxes following ponderosa pine restoration treatments. Ecol. Appl. 15, 1581-1593. doi: 10.1890/04-0868

Kelly, A., and Goulden, M. (2008). Rapid shifts in plant distribution with recent climate change. Proc. Natl. Acad. Sci. USA 105, 11823-11826. doi: 10.1073/pnas.0802891105

Kerhoulas, L. P., Kolb, T. E., and Koch, G. W. (2017). The influence of monsoon climate on latewood growth of southwestern ponderosa pine. Forests 8:140. doi: 10.3390/f8050140

Klos, P. Z., Link, T. E., and Abatzoglou, J. T. (2014). Extent of the rain-snow transition zone in the western US under historic and projected climate. Geophys. Res. Lett. 41,4560-4568. doi: 10.1002/2014GL060500

Larreta, B., Lopez-Sanchez, C., Corral-Rivas, J. J., López-Martínez, J., AguirreCalderón, C., and Álvarez González, J. G. (2017). Allometric equations for estimating biomass and carbon stocks in the temperate forests of north-western Mexico. Forests 8:269. doi: 10.3390/f8080269

McLane, S. C., Aitken, S. N. (2012). Whitebark pine (Pinus albicaulis) assisted migration potential: testing establishment north of the species range. Ecol. Appl. 22, 142-153. doi: 10.1890/11-0329.1

Molina-Terrén, D. M., Fry, D. L., Grillo, F. F., Cardil, A., and Stephens, S. L. (2016). Fire history and management of Pinus canariensis forests on the 
western Canary Islands Archipelago, Spain. Forest Ecol. Manage. 382, 184-192. doi: 10.1016/j.foreco.2016.10.007

Mueller, S. E. (2019). The influence of climate on burn severity in the Southwestern, US from 1984 to 2015 (M.S. thesis). Northern Arizona University, Flagstaff, AZ, United States.

Musálem, M. A., and García, S. M. (2003). Monografía de Pinus leiophylla. Libro Técnico Núm. 8, Instituto Nacional de Investigaciones Forestales, Agrícolas, y Pecuarias, Chapingo, Mexico.

Návar, J., de Jesús Rodríguez-Flores, F., Domínguez-Calleros, P. A. (2013). Taper functions and merchantable timber for temperate forests of Northern Mexico. Ann. For. Res. 56, 165-178. doi: 10.15287/afr.2013.51

Ogle, K., Whitham, T. G., and Cobb, N. S. (2000). Tree-ring variation predicts likelihood of death following severe drought. Ecology 81, 3237-3243. doi: 10. 1890/0012-9658(2000)081[3237:TRVIPP]2.0.CO;2

Ouzts, J., Kolb, T., Huffman, D., and Sánchez Meador, A. (2015). Post-fire ponderosa pineregeneration with and without planting in Arizona and New Mexico. For. Ecol. Manage. 354, 281-290. doi: 10.1016/j.foreco.2015.06.001

Owen, S. M., Sieg, C. H., Sánchez-Meador, A. J., Fulé, P. Z., Iniguez, J. M., Baggett, L. S., et al. (2017). Spatial patterns of ponderosa pine regeneration in high-severity burn patches. For. Ecol. Manage. 405, 134-149. doi: 10.1016/j.foreco.2017.09.005

Parks, S. A., Dobrowski, S. Z., Shaw, J. D., and Miller, C. (2019). Living on the edge: trailing edge forests at risk of fire-facilitated conversion to non-forest. Ecosphere 10:e2651. doi: 10.1002/ecs2.2651

Patterson, A., Flores-Rentería, L., Whipple, A., Whitham, T., and Gehring, C. (2018). Common garden experiments disentangle plant genetic and environmental contributions to ectomycorrhizal fungal community structure. New Phytol. 221, 493-502. doi: 10.1111/nph.15352

Pecl, G. T., Araujo, M. B., Bell, J. D., Blanchard, J., Bonebrake, T. C., Chen, I. C., et al. (2017). Biodiversity redistribution under climate change: impacts on ecosystems and human well-being. Science 355:aai9214. doi: $10.1126 /$ science.aai9214

R Core Team (2019). R: A Language and Environment for Statistical Computing. Vienna: R Foundation for Statistical Computing. Available online at: https:// www.r-project.org/ (verified January 3, 2020).

Rehfeldt, G. E., Crookston, N. L., Warwell, M. V., and Evans, J. S. (2006). Empirical analyses of plant-climate relationships for the western United States. Int. J. Plant Sci. 167, 1123-1150.

Rodriguez-Banderas, A., Vargas-Mendoza, C., Buonamici, A., and Vendramin, G. (2009). Genetic diversity and phylogeographic analysis of Pinus leiophylla: a post-glacial range expansion. J. Biogeogr. 36, 1807-1820. doi: 10.1111/j.1365-2699.2009.02104.x

Rodríguez-Trejo, D. A., and Fulé, P. Z. (2003). Fire ecology of Mexican pines and a fire management proposal. Int. J. Wildland Fire 12, 23-37. doi: 10.1071/WF02040

Sáenz-Romero, C., Refeldt, G. E., Ortega-Rodríguez, J. M., Marín-Togo, M. C., and Madrigal-Sánchez, X. (2015). Pinus leiophylla suitable habitat for 1961-1990 and future climate. Bot. Sci. 93, 709-718. doi: 10.17129/botsci.86

Sangüesa-Barreda, G., Camarero, J. J., Oliva, J., Montes, F., and Gazol, A. (2015). Past logging, drought and pathogens interact and contribute to forest dieback. Agric. For. Meteorol. 208, 85-94. doi: 10.1016/j.agrformet.2015.04.011

Schiede ex Schlechtendal et Chamisso (1831). “Pinus leiophylla.” The Gymnosperm Database. Available online at: https://www.conifers.org/pi/Pinus_leiophylla. php

Seager, R., Ting, M., Held, I., Kushnir, Y., Lu, J., Vecchi, G., et al. (2007). Model projections of an imminent transition to a more arid climate in Southwestern North America. Science 316, 1181-1184. doi: 10.1126/science.1139601

Shinneman, D. J., Means, R. E., Potter, K. M., and Hipkins, V. D. (2016). Exploring climate niches of ponderosa pine (Pinus ponderosa Douglas ex Lawson) haplotypes in the western United States: implications for evolutionary history and conservation. PLoS ONE 11:e0151811. doi: 10.1371/journal.pone.0151811

Shirk, A. J., Cushman, S. A., Waring, K. M., Wehenkel, C. A., Leal-Sáenz, A., Toney, C., et al. (2018). Southwestern white pine (Pinus strobiformis) species distribution models project a large range shift and contraction due to regional climatic changes. For. Ecol. Manage. 411, 176-186. doi: 10.1016/j.foreco.2018.01.025
Shive, K. L., Sieg, C. H., and Fulé, P. Z. (2013). Pre-wildfire management treatments interact with fire severity to have lasting effects on post-wildfire vegetation response. For. Ecol. Manage. 297, 75-83. doi: 10.1016/j.foreco.2013.02.021

Singleton, M. P., Thode, A. E., Sánchez Meador, A. J., and Jose Iniguez, M. (2019). Increasing trends in high-severity fire in the southwestern USA from 1984 to 2015. For. Ecol. Manage. 433, 709-719. doi: 10.1016/j.foreco.2018.11.039

Speer, J. H. (2010). Fundamentals of Tree-Ring Research. Tucson, AZ: The University of Arizona Press.

Stokes, M. A., and Smiley, T. L. (1968). An Introduction to Tree-Ring Dating. Tucson: The University of Arizona Press.

Strom, B. A., and Fulé, P. Z. (2007). Pre-wildfire fuel treatments affect longterm ponderosa pine forest dynamics. Int. J. Wildland Fire 16, 128-138. doi: 10.1071/WF06051

Swetnam, T. W., and Baisan, C. H. (2003). "Tree-ring reconstructions of fire and climate history in the Sierra Nevada and southwestern United States," in Fire and Climate Change in Temperate Ecosystems of the Western Americas, eds T. T. Veblen, W. L Baker, G. Montenegro, and T. W. Swetnam (New York, NY: Springer), 158-195.

Truettner, C., Anderegg, W., Biondi, F., Koch, G., Ogle, K., Schwalm, C., et al. (2018). Conifer radial growth response to recent seasonal warming and drought from the southwestern USA. For. Ecol. Manage. 418, 55-62. doi: 10.1016/j.foreco.2018.01.044

USDA Forest Service, Apache-Sitgreaves National Forests (2019). ApacheSitgreaves National Forests GIS Data. Available online at: https://www.fs.usda. gov/detail/r3/landmanagement/gis/?cid=stelprdb5202663 (accessed March 15, 2019).

Velmex Positioning System (2017). Measure J2X Application. Bloomfield, NY: VoorTech Consulting.

Waring, K. M., Reboletti, D. M., Mork, L. A., Li, M., Huang, C.-H., Hofstetter, R. W., et al. (2009). Modeling the impacts of two bark beetle species under warming climate in the southwestern U.S.A.: ecological and economic consequences. Environ. Manage. 44, 824-835. doi: 10.1007/s00267-009-9342-4

Western Regional Climate Center (2017). Available online at: https://wrcc.dri.edu (accessed March 12, 2019).

Whittaker, R. H., and Niering, W. A. (1975). Vegetation of the santa catalina mountains, Arizona. V. Biomass, production, and diversity along the elevation gradient. Ecology 56, 771-790. doi: 10.2307/1936291

Willyard, A., Gernandt, D. S., Potter, K., Hipkins, V., Marquardt, P. Mahalovich, M. F., et al. (2017). Pinus ponderosa: a checkered past obscured four species. Am. J. Bot. 104, 161-181. doi: 10.3732/ajb.16 00336

Yang, B., Qin, C., Wang, J., He, M., Melvin, T. M., Osborn, T. J., et al. (2014). Precipitation history on the Tibetan Plateau. Proc. Natl. Acad. Sci. U.S.A. 111, 2903-2908. doi: 10.1073/pnas.13192 38111

Yazzie, J. O., Fulé, P. Z., Kim, Y. S., and Sánchez Meador, A. (2019). Diné kinship as a framework for conserving native tree species in climate change. Ecol. Appl. 29:e01944. 10.1002/eap.1944. doi: 10.1002/eap.1944

Yocom Kent, L. L., Fulé, P. Z., Brown, P. M., Cerano-Paredes, J., Cornejo-Oviedo, E., Cortés Montaño, C., et al. (2017). Climate drives fire synchrony but local factors control fire regime change in Northern Mexico. Ecosphere 8:e01709. doi: $10.1002 /$ ecs 2.1709

Yocom, L. L., Jeness, J., Fulé, P. Z., and Thode, A. (2019). Previous fires and roads limit wildfire growth in Arizona and New Mexico, USA. For. Ecol. Manage. 449:117440. doi: 10.1016/j.foreco.2019.06.037

Conflict of Interest: The authors declare that the research was conducted in the absence of any commercial or financial relationships that could be construed as a potential conflict of interest.

Copyright (c) 2020 Hess and Fulé. This is an open-access article distributed under the terms of the Creative Commons Attribution License (CC BY). The use, distribution or reproduction in other forums is permitted, provided the original author(s) and the copyright owner(s) are credited and that the original publication in this journal is cited, in accordance with accepted academic practice. No use, distribution or reproduction is permitted which does not comply with these terms. 